\title{
Use of Output Specifications in PFI Housing Projects - How They Differ from Prescriptive Specifications
}

\author{
Patrick T.I. Lam ${ }^{1}$, Albert P. C. Chan ${ }^{2}$, Akintola Akintoye ${ }^{3}$ and Arshad Ali Javed ${ }^{4}$
}

\begin{abstract}
In many parts of the world, low cost housing used to be built and maintained by the governments, based on designs and detail specifications prepared by the public sector with construction carried out by contractors. Results vary due to differences in design standards, workmanship and property management, depending also on the neighbourhood's care of the estates and their pattern of usage. In the UK, where Private Finance Initiative (PFI) has been used for infrastructure projects, there have been successful cases of city estate being transformed by PFI. These PFI housing schemes involve new-build, refurbishment as well as facility management. Unlike traditional construction, which is based on prescriptive specifications, PFI housing is based on output specifications. A study has been undertaken to compare the two specification approaches as they are applied to housing estate. Results are enlightening and serve as good reference to cities such as Hong Kong SAR and Singapore, where public housing provisions have been a major concern of their citizens as the building stock gets older.
\end{abstract}

Keywords: Housing, Private Finance Initiative, Output Specifications, Comparison

\section{INTRODUCTION}

As the building stock ages, refurbishment or redevelopment will take place. Governments in different parts of the world adopt various strategies in coping with the task of bringing their housing estates up to modern day standards. Some housing authorities, such as those in Hong Kong and Singapore, choose to retain planned and preventive maintenance as part of the public sector responsibilities and outsource the major renovation works, using traditional construction specifications as the tender and contract basis. Others, such as the UK government, has adopted the Private Finance Initiative (PFI) approach in some of their rehousing projects, based on output specifications for construction, property management and service provisions.

Private Finance Initiative is the principal model in the UK under the broader name of Public Private Partnership. Under the PFI arrangement, the public sector contracts to purchase built assets and services on a long-term from the private sector, which usually provides the necessary finance and shares the risks with the former. The PFI model has been used for hospitals, schools, toll-roads and prisons. Whilst the political backgrounds of PFI have yet to be debated, larger local authorities in the UK have mostly experienced with this procurement approach [1]. Unlike the traditional procurement approach for which tenders for construction only are invited based on designs prepared by client-appointed consultants, PFI bids are invited based on output specifications, which state the requirements of the authorities in terms of asset and service performance. In the traditional scenario, the specifications forming part of the consultants' design would prescribe materials and workmanship, whereas an output specification would only state the end results expected. Payments for PFI works are usually effected through unitary charges multiplied by the number of units made available, less deductions for any performance shortfalls when measured against the output specification.

\section{HOUSING PFI IN THE UK}

A GBP19 billion backlog of repairs and modernisation work was identified by 2000 for UK's council housing stock. Not long after, the Decent Home standards were promulgated when the Housing Health and Safety Rating System (HHSRS) replaced the unfitness standard as the statutory minimum standard. The new standards for housing have four criteria, as extracted from the website of the Department of Communities and Local Government [2], all to be met by 2010:-

1. It meets the current statutory minimum standard for housing (i.e. the dwelling should be free of category 1 hazards under the HHSRS)

\footnotetext{
${ }^{1}$ Associate Professor, Dept of Building \& Real Estate, The Hong Kong Polytechnic University, Hung Hom, Kowloon, Hong Kong, bsplam@ polyu.edu.hk (*Corresponding Author)

${ }^{2}$ Professor, Dept of Building \& Real Estate, The Hong Kong Polytechnic University, Hung Hom, Kowloon, Hong Kong, bsachan@polyu.edu.hk

${ }^{3}$ Professor and Head, Sch. of Built \& Natural Environment, University of Central Lancashire, Harris Building, Corporation Street, Preston, Lancashire, UK, aakintoye@uclan.ac.uk

${ }^{4}$ Research Student, Dept of Building \& Real Estate, The Hong Kong Polytechnic University, Hung Hom, Kowloon, Hong Kong, 09902780r@polyu.edu.hk
} 
2. It is in a reasonable state of repair

3. It has reasonably modern facilities and services

4. It provides a reasonable degree of thermal comfort.

These spurred a government policy to stimulate additional investment in local authority housing and PFI was one of the options made available for Housing Revenue Account (HRA) properties. The aims were to regenerate areas where demand for social housing was high but the condition of existing stock was poor and to create more sustainable communities [3]. Under PFI arrangement, management of the housing stock becomes the responsibility of the private sector contractor, whilst the local authority continues to own the housing and retains its tenants [4]. Sometimes, private homes in the vicinity are also improved at the same time, with external improvements and boundary improvements funded under the Private Sector Capital Programme of city councils. Seven pathfinder PFI schemes were launched, including refurbishment of traditional housing estates, high rise tower blocks, as well as street properties mixed with private properties. The contract periods ranged from 15 to 30 years, commencing from various dates from 2003 to 2006 . A comprehensive review of the baseline was undertaken in 2008 by a firm called PA Consulting on behalf of the Department for Communities and Local Government, with a view to look for areas of possible improvement for the future. As shown by the residents' survey prior to the Housing PFI intervention, there were significant levels of dissatisfaction with houses and living conditions in the areas. To-date, although still being premature to judge the overall success of these pathfinder schemes, they are progressing well and the stakeholders are happy with what has been achieved in improving housing stock to the Decent Homes standard [4].

The emphasis of Housing PFI is on the use of output based specification, by which flexibility is left to the private contractor to find the most cost-effective means of delivering the required outputs. In traditional projects, the contractor is just bound to deliver whatever is specified by the design team with little scope for innovations.

\section{TRADITIONAL HOUSING PROJECTS - HOW THEY HAVE BEEN PROCURED}

In the UK, the content and format of drawings, specifications, and bills of quantities appear to have changed little over time [5], particularly in the housing sector. For traditionally procured contracts, prescriptive specifications describe the materials and workmanship standards required to achieve required quality. For public works, proprietary product brand names are not used so that all relevant manufacturers can compete based on the specified properties. An alternative is to add wordings such as "or equal approved" to allow some choice [6]. Codes of practice and British Standards are frequently stated to indicate the level of workmanship required. Some efforts have been made in the 1980s through the Co-ordinated Project Information movement to improve communication, but the essence of specifications remains. For housing refurbishment works, a combined form of specification and quantities has been used, with elaborate descriptions on tasks such as taking down existing works and protection [7], When Design and Build projects became more common, the use of performance specifications was advocated [8]. In the last decade, with the increased use of PFI in housing, performance specifications have evolved into Output Specifications covering service elements as in Facilities Management.

\section{CHARACTERISTICS OF OUTPUT SPECIFICATIONS}

An output specification should aim to detail what needs to be achieved, but not how to do it. Any undesirable effects should also be stated. Each output should have defined performance targets, preferably measurable. These targets should be aligned with the payment mechanism (which is a separate document), since shortfalls in achievement will carry the penalty of payment deduction.

In a Housing PFI situation, the output specification will typically cover some or all of the following:

- Provision of new build accommodation

- Refurbishment or alterations to existing housing

- Maintenance of properties to agreed Property Management Standards, Service Performance Standards comprising:

- Tenant management

- Estate management and maintenance

- Caretaking and

- Information Technology

Property Management Standards define the physical standards to which each dwelling needs to be maintained and hence define the standard which the dwellings must reach to be regarded as being available for occupation. The Service Performance Standards define the expected service delivery outcomes.

A Stock Condition Survey should be undertaken before the outline business case is established for each Housing PFI project and the results should be reflected in the output specification. The output specification (OS) will be increasingly refined over the procurement process as follows:

1. Invitation for Expression of Interest - a summary of the key elements of the draft OS;

Outline Business Case - a draft OS together with a commentary on how it will be further developed; Invitation to Negotiate - fully developed OS for discussion and refinement up 
to contract signature.

\section{EXAMPLES OF OUTPUT SPECIFICATION FOR PFI HOUSING}

Most PFI Housing contracts include construction of new homes, refurbishment of retained ones and housing management. The following examples regarding the service elements (in italics) are extracted from the output specifications of two successful PFI schemes in the UK with a total of over 4,000 dwellings. These specifications provided reference to the Housing PFI Procurement Pack produced later by the Local Partnerships, which incorporate 4ps [9].

\section{A. Estate Management}

The performance requirements are spelt out rather than the details on methods, giving the contractor flexibility, as shown in the example below:

1) The Contractor is required to manage all Tenancy matters including:-

i) anti-social behaviour (such as drug dealing, noise nuisance, control of pets, garden and home condition management) and racial harassment;

ii) succession;

iii) lodgers;

iv) alterations to Retained Properties (designated for homeless people);

v) joint tenancies;

vi) squatting;

vii) vandalism;

viii) damage to Retained Properties;

ix) breaches of Tenancy conditions; and

$x$ ) parking (authorised and unauthorised) and lowering of kerbs.

2) The Contractor is also required to provide a Support Service for Tenants and other persons legally entitled to occupy the Retained Properties with special needs.

3) The Contractor is required to provide the estate management service in respect of the whole of the Project Area irrespective of tenure. The Contractor is required to take legal steps as agent of the Council if appropriate in enforcing Tenancies and lease covenants or as may otherwise be required in order to properly perform the estate management service.

4) The Contractor is also required to provide the estate management service in such manner as will:

$i$ fulfil the Council's statutory and contractual duties;

ii. $\quad$ enable Tenants and other persons legally entitled to occupy a property on the Estate to have quiet enjoyment of such property.
B. Maintenance of Components to Modern Standard Apart from the Decent Homes Standards, the Contractor is responsible for maintaining components to Modern Standard within the concession period. A table is given in the OS that differentiates the age-based maintenance standard of different building components. For example, roofs, window frames and doors are stipulated as 30 years; electrical wiring 30 years; bathroom and WC equipment 20 years; central heating boiler 16 years and painted surfaces 7 years, etc.

\section{Vulnerable Tenants}

Within the OS, special care is given to Vulnerable Tenants, who are defined as parents with one or more children under 6 years old, or adults over 60 years of age, or any person with a health problem which may be aggravated by lack of heat or a pregnant person, As long as this category of tenants identifies themselves as such, the Contractor is responsible for a shorter rectification period of heating and metering defects, especially in the winter season.

\section{Neighbourhood Management}

The Contractor is required to take reasonable steps to (extracts in italics):

1) reduce crime, fear of crime and improve the environment;

2) reassure vulnerable community members and act as friendly and supportive figures to local people and visitors;

3) foster social inclusion, particularly in relation to children and young people, the unemployed, homeless people, black and minority ethnic communities, asylum seekers and any other socially excluded group; and

4) support neighbourhood management by adding value and contributing to the work of local initiatives, projects and services so that they are joined up and sensitive to local needs.

According to a study report commissioned by the Department of Communities and Local Government [3], the standard service level was compared favourably with the specified Minimum Tolerable Level (MTL), as extracted below in italics. Where the MTL was not met, action was taken against the contractor based on the deductions stipulated in the Payment Mechanism document.

- average re-let time of 32 days or below (MTL = 37 days or more $)$

- $\quad 99 \%$ or above of urgent repairs carried out within Government timescales (MTL = below 97\%)

- 11 days or below to complete non urgent 
repairs $(M T L=12$ days and above)

- $95 \%$ or more repairs completed on time $(M T L=$ below $90 \%)$

- $\quad 85 \%$ or more repairs completed on first visit $(M T L=$ below $80 \%)$

- $95 \%$ and above re-housing applicants receive an appointment for re-housing within 10 days of request

\section{EMPIRICAL STUDY ON HOUSING PFI OUTPUT SPECIFICATIONS}

In order to evaluate the effectiveness of Housing PFI output specifications, a structured interview was conducted in May 2010 with senior management personnel of the city council in charge of two PFI schemes mentioned above (one in the Pathfinder scheme and one in the Round 2) in the Northwest region of the UK, both having new-builds as well as remodelling of existing houses. The themes of the interview are given as sub-headings below, followed by a summary of the responses:

\section{A. Basis of standard and innovation}

The Decent Homes standards of the UK government is the directive and local authorities or tenants can decide on the level of quality above the stipulated minimum (e.g., kitchens should not be more than 20 years old and bathrooms not more than 30 years old). Tenant associations form a steering group (7-8 members) with councilors and participate in the decision making process. Housing needs were the overriding factor instead of income arising from the regeneration.

To invite innovation, for example, the heating system was specified by time to heat up rather than the traditional specifications. Space heating is also specified by performance. There are also innovations on service delivery.

There are no prescriptive elements, apart from things like fire alarms, since there are not much alternative for such simple items.

\section{B. Change/variation management and cost implications}

The first project adopted a flexible approach, so changes were not documented. The later scheme was more formalised. An example of change is the fencing around housing units, which was initially designed to be low, but residents prefer higher fencing. Contractor did not claim extras.

Given a specified performance level, the bidders proposed their own approaches. For example, the staffing level was changed for customer service centre with corresponding change in opening time - a nominal saving of GBP 5,000 was made.

As to the nature of other changes, the refurbishment standard was developed over time, e.g., the rating for energy standard was raised in line with Standard Assessment Procedure (SAP) rating, the UK mandatory environmental rating system for dwellings. There was an interim performance standard, which has evolved into a fully operational standard.

The standard of refurbishment has caused some confusion, e.g., in respect of boundary treatment, normally if it is within $1 \mathrm{~m}$ from main road, there will be brick fencing. But it is not easy to distinguish between main road and minor road. Boiler standard is another example.

Due to climate change, there was a change in the energy performance certificate on empty houses for social housing.

\section{Performance monitoring, management and tools}

A self-monitoring system on housing service is adopted with monthly performance report. Since a partnering approach is taken, there is no detail checking (tenants sit on a monitoring panel and would reflect any major discrepancies), but if things are not right, auditing would be carried out. Housing allocation, however, remains with the Council.

Apart from unitary charges, there is no direct incentive, but an indirect incentive is in place, e.g., when the contractor cannot collect rent up to $98 \%$ within a 3-year period, an amount of GBP 12,000 will be deducted. Yet, if the contractor manages to recover rent in arrears, there will be saving (i.e., the contractor earns back the deducted amount).

\section{Critical Success Factors}

Standardisation is important, so that there is no need for local authorities and contractor to keep going back and do re-checks. Since the Pathfinder projects, there have been many improvements made in documentation. Yet, the basis of performance measurement still needs to be made clear.

Early lessons learnt from the Pathfinder projects also point to the importance of ensuring deliverability of output specifications by taking into consideration the capabilities of the market and the estimated affordability of the councils. It is also vital to align the output specification with the payment and performance measurement mechanisms. The output specification should be realistic given the conditions of the housing stock and the environment, as should the triggers for performance deduction. The remedies should reflect the consequence of the failure [10].

\section{INNOVATIONS}

Apart from the theory of communication, which has focused on the clarity of expressions and readability of contract documents [11], the use of specifications in defusing innovations has been quoted by Emmitt and Yeomans [6] based on the works of Rogers [12]. This can be taken further in the possibility of encouraging innovations by the private sector in PFI housing schemes through the use of output specifications. It stems from the requirements that the private sector has 
to respond to the clients' needs through the submission of method statements after contract award, but this can be done earlier in the bid evaluation phase, which would enhance the bid competiveness. Throughout the life cycle of operation and maintenance, the private sector is also motivated to innovate on cost saving and efficiency measures, whilst still meeting the output requirements of the public sector clients. An example is the selfinitiated use of more energy efficient installations during replacement cycles. This cannot be achieved by the prescriptive way of specifying.

\section{HINTS FOR APPLICATIONS IN ASIAN CITIES}

The PFI approach for housing development and regeneration has accumulated a wealth of knowledge and experience towards the private provision of housing needs and management in cities which have undergone a rapid growth of population and their mass housing is on the brink of renewal. Hong Kong SAR and Singapore alike, have built up public housing to meet the needs of their citizens to the proportions of 50 and 80 percent respectively. Historically, construction has been outsourced through public tendering based on prescriptive specifications. In the early 90s, Hong Kong launched the Private Sector Participation Scheme (PSPS), whereby the private sector was invited to finance, design, construct and maintain middle-income housing and the model was based on leasehold land, for which developers paid a subsidised premium in exchange for the right of such development. Completed units were sold at discounted market prices as stipulated by the government. The specifications for construction were prepared based on guidelines provided by the Housing Authority. This type of housing was, however, stopped after the Asian economic crisis, which sent the sale of private properties into doldrums. Now that property prices have surged again, calls are now being made for the re-provision of more middle-income housing for sale to the younger generations. The private sector can help to meet this need through building new PSPS flats at affordable prices and providing estate management services based on output specification instead of prescriptive specification to encourage innovations in the project life cycle.

In Singapore, in addition to the public housing programme being implemented by the government, an arrangement was made with organizations such as the National Trade Union Congress for developing what was known as Executive Condominiums. The Housing Development Board in Singapore also launched a number of Design and Build projects based on performance specifications, but estate management was taken care of by the Board itself, jointly with Town Councils. All the while, public housing for renting has been in the reign of public management. As the existing building stock is ageing fast, it is time for a re-think and the UK PFI Housing scene may offer some lessons, especially in the way that maintenance and services are specified to achieve the ends without stating the means to leave room for the private sector to contribute what they are good at doing.

\section{CONCLUSION}

This paper is part of a larger research project with the objective of studying the uses and impacts of output specifications in PPP or PFI projects, including housing and infrastructure provisions such as schools and hospitals. The characteristics of output specifications as outlined in this paper are common across different sectors, in that measurable performance targets are stipulated for the physical assets and services by the public agency, leaving the contractors to innovate and achieve them. Failure to do so would attract a financial penalty since payments would be deducted from a unitary charge otherwise disbursable regularly during the life time of the project based on availability. As such, the contractor is motivated to ensure that the output specifications are met as far as possible in the project life cycle. With proper risk allocation and a robust contractual structure, this approach can be an effective way for procuring asset and services from the private sector for public use. In light of the Housing PFI experience as delineated in this paper, output specifications seem to have served their purposes and lessons are worth learning by Asian cities which are undergoing rapid ageing of their existing public housing stock in the near future.

\section{ACKNOWLEDGEMENTS}

The work described in this paper was supported by a grant from the General Research Allocation of the Hong Kong Polytechnic University (Project No. G-U605) and a grant from the General Research Fund (PolyU 5214/09E) of the Research Grant Council in Hong Kong SAR.

Special thanks are also due to the interviewees of the PFI Housing schemes in the UK, who shared their valuable experience, insight and specification samples.

This is a revised version of the paper presented at the 2011 International Conference on Construction Engineering and Project Management (ICCEPM), coorganized by the University of New South Wales, Australia, Korea Institute of Construction Engineering and Management as well as the Nanyang Technological University of Singapore on 16-18 February 2011 in Sydney, Australia. The valuable comments of anonymous reviewers are gratefully acknowledged.

\section{REFERENCES}

[1] M. Beck, C. Hunter, "Private finance initiative uptake in UK local authorities", in Public Private Partnerships: Managing risks and opportunities, Eds. A. Akintoye, M. Beck, C. Hardcastle, Blackwell Publishing, pp. 369-383, 2003.

[2] Department of Communities and Local Government website: http://webarchive.nationalarchives.gov.uk/+/http://www.commu nities.gov.uk/housing/decenthomes/whatis/, [accessed on $20 \mathrm{Nov}$ 2010] 
[3] PA Consulting, "The Private Finance Initiative for Housing Revenue Account Housing", The Pathfinder Schemes Baseline Report, Department for Communities and Local Government, UK, 2008.

[4] HCA, "Housing PFI", Housing and Communities Agency, http://www.homesandcommunities.co.uk/housing pfi, [accessed on 19 Nov 2010]

[5] R.F. Moore, "Specification and purchasing within traditional contracting", Technical Information Service, Paper 82 The Chartered Institution of Building, 1987.

[6] S. Emmitt, D.T. Yeomans, "Specifying Buildings: a design management perspective", Butterworth Heinemann, 2001.

[7] RICS, "Refurbishment and alteration work - Quantity surveying documentation", Quantity Surveying Division, Royal Institution of Chartered Surveyors, 1982.

[8] JCT, "The JCT Guide to the use of performance specifications", Joint Contracts Tribunal, 2001

[9] Local Partnerships, "Housing PFI Procurement Pack - Part 5: The Output Specification", in Housing Pack 2009 Guidance, Local Partnerships LLP, 2009.

[10] PA Consulting, "Private Finance Initiative (PFI) for Housing Revenue Account Housing - Early Lessons from the Pathfinder Programme", A report for the Office of the Deputy Prime Minister, June 2003.

[11] R. Rameezdeen, C. Rajapakse, "Contract interpretation: the impact of readability", Construction Management and Economics, vol. 25, no. 7, pp. 729-737, 2007.

[12] E.M. Rogers, "Diffusion of Innovations", $4^{\text {th }}$ ed., The Free Press, New York, 1995. 